\title{
Second phase transnationalism: reflections on launching the SCMS transnational cinemas scholarly interest group
}

\author{
Austin Fisher and lain Robert Smith \\ Media Production Department, Bournemouth University, Poole, UK; Department of Film Studies, Kings \\ College London, London, UK
}

\begin{abstract}
This article examines what the process of founding and chairing the SCMS (Society for Cinema and Media Studies) 'Transnational Cinemas' scholarly interest group revealed to the authors about the evolution of the field. Charting a progression in the group's activities from workshops around disciplinary definition to more practical sessions addressing teaching and research methodologies, the article maps out key shifts that took place within the period 2013-2017. It also appraises the authors' efforts to create lasting, tangible resources for future researchers and teachers. The limitations of such a group's influence are balanced against its capacity to bring scholars from diverse disciplines into dialogue with each other, thereby offering insight into the breadth and depth of the 'transnational cinemas' field.
\end{abstract}

\section{KEYWORDS}

SCMS; Scholarly Interest

Group; Transnational

Cinemas; pedagogy;

methodologies

In her contribution to The Routledge Companion to World Cinema, Deborah Shaw reflects on recent developments within the field of transnational cinema studies. After mapping out the manner in which the first phase of transnational film criticism primarily concerned itself with 'setting out terms of reference... [and] providing definitions for the transnational' $(2017,292)$, Shaw notes that:

Perhaps we can identify the development of the Transnational Cinemas Scholarly Interest Group (SIG) in 2013 for the Society for Cinema and Media Studies, run by Austin Fisher and Iain Smith, as a possible starting point for the second phase [of transnational film studies] ... the SIG has brought researchers into dialogue with each other, enabling them to trace the breadth of this concept and its application and to chronicle it ... the range of workshops and panels demonstrates that there were few areas within Film Studies on which transnational cinema had not left its imprint. (Shaw 2017, 296-297)

To have our role in co-founding the scholarly interest group cited as a possible starting point for a 'second phase' of transnational film studies was both gratifying and surprising. Neither of us would claim to have produced transformative works within the field on the level of Shaw's own contributions (Shaw 2013, 2017), or indeed those of other scholars such as Hjort (2009), Higbee and Lim (2010) or Berry (2010), and the effectiveness (or otherwise) of our period at the helm of the group will perhaps only become fully clear in the coming years. Nevertheless, it was certainly our goal to make 
a clear intervention within transnational film studies by helping move the field of study beyond debates over definition towards more practical discussions about how to apply a transnational perspective across a range of different contexts. If we have been partly responsible for shepherding the second phase of the field, therefore, the responsibility lies less in any particular theoretical intervention that we have ourselves made than in our role in bringing together scholars from across the discipline to explore and debate the future direction of the field.

In 2012, when we were first formulating the idea for the scholarly interest group, we were concerned that the field was largely dispersed across various national and regional cinema specialisms, which meant we weren't always communicating effectively with each other. We noticed that scholars were tending to specialise in transnational approaches to particular national cinemas and therefore were primarily attending panels and conferences in those specific areas, with the result that the insights into transnational film studies were not always being effectively shared across the discipline. ${ }^{1}$ Sessions we attended at the 2012 SCMS conference in Boston would often become side-tracked by definitional discussions around what we mean by the 'transnational' (seemingly oblivious to similar discussions taking place at other 'transnational' panels at the same conference), and we felt that there needed to be progress towards more practical applications of the transnational framework. We were also aware that numerous scholars had expressed concern that the transnational risked becoming a 'potentially empty, floating signifier' (Higbee and Lim 2010, 10) and perhaps little more than a 'fashionable word with no distinct meaning of its own' (Berry 2010, 115). We believed that the discipline would benefit greatly from the formation of a scholarly interest group that could function as a hub for these debates - offering a pluralistic approach that would bring together scholars from across these various subfields in order to generate discussion around the future of transnational cinemas scholarship.

As we explained in our Mission Statement to the SCMS board, there was a pressing need for a scholarly interest group that could help shape these emerging debates given that:

There is no consensus over whether the phrase 'transnational cinema' describes processes of industrial collaboration across borders, of the 'localisation' of filmic products as they traverse the globe, or of foreign influences coming to bear upon the production of the film text ... The debates here summarised are seldom undertaken in a programmatic manner. More often, 'transnational', 'international', 'transcultural' or 'global' appellations are used as interchangeable buzz-words.

The energy and vitality of the 'transnational turn' (Hjort 2009, 13) within film studies, therefore, came with attendant dangers of loose and unreflexive usages of the term leading to it 'becoming too contradictory and too similar to many other terms to be useful' (Berry 2010, 114). With this in mind, we designed the SIG to address what we felt was an urgent need for scholars to work together, to address exactly what this shift away from considerations of the 'national' has meant for our scholarship and for our teaching.

In this article, therefore, we intend to map out the shifts that took place over the course of our four-year tenure as co-chairs of the scholarly interest group (2013-2017) and relate these to broader adjustments within the field of study. By identifying specific panels and workshops that we felt were particularly productive, we intend to tease out 
some of the implications of these emerging debates surrounding cinematic transnationalism. Broadly speaking, our tenure began with a series of sessions devoted to questions of definition, and then gradually moved towards more practical applications - such as workshops on disciplinary boundaries, teaching strategies and videographic criticism although, as our experiences suggested, we may never be entirely free of those debates regarding definition.

\section{Establishing the SIG}

When we set up the SIG, we were aware of Will Higbee and Song Hwee Lim's proposal that a politically engaged 'critical' form of transnationalism should not only interrogate the power dynamics within cinematic border crossings but should also 'extend to our own critical practice as film scholars who enjoy the privilege of being located within an anglophone academia' (Higbee and Lim 2010, 18). Indeed, as two white British scholars who at that point were primarily known for our work on the Italian Western (Fisher) and transnational remakes of Hollywood (Smith), we were particularly attuned to the criticism that the shift from a 'world cinema' to a 'transnational cinemas' framework risks recentring Hollywood within discussions of cinematic practice globally. We consciously wanted to avoid building an Anglo-centric community of transnational cinema scholars that risked replicating, or worse falling deeper into, the perspectival problems inherent within world cinema scholarship. Specifically, we wished to avoid reinforcing what Lúcia Nagib describes as the 'binary division of the world, according to which Hollywood deserves a different treatment from all other cinemas' (Nagib 2006, 32). With this in mind, we were conscious when we were selecting panels and workshops to sponsor at SCMS that our primary purpose was to reflect the diversity of approaches and foci at the conferences. Of course, this selection process was also shaped by more logistical factors such as our desire to avoid clashes in our SIG timetable, but nevertheless, we were aware of our responsibility to highlight the plurality of the emerging field and to avoid reproducing the discipline in our own image.

The mixed results of these attempts to embrace a range of approaches and areas of expertise can be observed on a purely quantitative level by surveying the titles of panels and workshops we sponsored between the 2013 and 2017 SCMS conferences (eight sessions per year, totalling forty over the five conferences in question). Unsurprisingly, the word 'transnational' is by far the most frequent, occurring twenty-six times across these session titles. Our continued grappling with terminologies can be observed by the fact that 'global' occurs three times; 'world' three times; 'national' or 'nationalism' three times; 'international' twice; 'transatlantic' twice; and 'transcultural' or 'transculturation' twice. While we were urging some level of consistency in our use of terminology, we were nevertheless aware that similar debates and discussions were being had within sessions using each of these alternative terms.

Such an exercise of surveying session titles simultaneously reveals both how our own subjective biases came to bear upon our role, and how a negotiation with received disciplinary boundaries has been a constant across this period. Since we both primarily specialise in 'popular' or 'genre' cinemas, it is unsurprising (if uncomfortable for us in hindsight) to note the consistent theme across the following panels: 'Transnational Science Fiction Film and Media'; 'Beyond the West: New Perspectives on International 
Westerns'; 'International Westerns in Context', 'European Horror Cinema and Transcultural Exchange'; 'Transnational Hybridity and the Contemporary European Horror Film'; 'Melodrama through a Transnational Lens: Questions of Methodology'; 'Transnational Film Remakes'; and 'Global Exploitation Cinemas: Travel, Translation, Taste'. On the one hand, this thematic strand provides a good illustration of Shaw's point that the SIG has helped to move transnational film studies beyond the privileging of 'proper' objects of study (that is, 'the expected work on migration, diasporic and (post)colonial cinemas') (Shaw 2017, 297). A less charitable reading might argue that our own particular research specialisms may have disproportionately influenced our selection of sessions. Both perspectives seem valid to us.

Another significant trend across the titles of our sponsored panels highlights a recurrent challenge for the field of transnational cinema studies more broadly. 'Contemporary Franco-American Face-Offs: Transatlantic Cinematic Encounters', 'Transnational Translations: Gender and Genre in South Asian Cinema', 'Hispanic Musicals: Nationalisms and Transnational Stars', 'Latin American Minor Cinemas in Europe: Transnational Trajectories and Ambivalent Belongings', 'Scandinavian Nymphomania: A National and Transnational Legacy', 'Israeli Cinema: Beyond the National', 'Transnational (Latin American) Genres' and 'Nordic Cinemas of Elsewhere: Global Circulations until the 1970s' are all notable for their disciplinary alignment with particular fields of area studies. Perhaps the single most revealing insight we gained in the process of attending these panels and inviting the panellists to our annual SIG meetings was that these diverse specialisms would likely not otherwise have been talking to each other about their closely related methodologies without the newlyformed SIG acting as a hub. As Lindsey Decker observed in her report for this journal on the SIG's activities at the 2016 SCMS conference in Atlanta,

the SIG meeting ... contained a brief, and quite positive, discussion of the broad diversity of opinions, subjects of study and methods within the field. It is through early and continued conversation and connection that we can stop transnational cinema studies from becoming merely a conglomeration of area studies wherein individual scholars say much the same thing about different cinemas without progressing the broader conversations of the subfield. (Decker 2017, 169)

Decker makes a crucial point here. While the broad sweep of our sponsored panels and workshops highlights persistent issues, which we addressed with varying degrees of success, the most tangible benefit of the SIG was its ability to bring people into sustained and focused face-to-face conversation about the direction of the field. In hindsight, three sessions in particular - from the 2014, 2015 and 2016 conferences stand out to us for how they enabled an increased emphasis on practical applications of the 'transnational' to our areas of study, to our teaching and to our research methodologies. It is revealing that all three were in the SCMS 'workshop' format - whereby short 'position pieces' are followed by an extended discussion involving everybody present - rather than the more traditional 'panel' format. ${ }^{2}$ 


\section{'Locating transnational cinema studies' workshop (SCMS 2014 - Seattle)}

We decided early on that, if the SIG was indeed to move on from an obsession with issues of definition, the questions of disciplinary 'belonging' identified above required careful and considered debate. We felt that it remained unclear whether 'transnational cinemas' genuinely constituted a distinct field within film scholarship since its key concerns are equally germane across a number of disciplines: most notably, area studies. If the objects of study are inherently nomadic then, frequently, so too were the research findings associated with them, dispersed across diverse disciplines and scholarly outlets.

This workshop, therefore, revisited debates that were pertinently raised in the inaugural issue of the Transnational Cinemas journal, concerning the risk of insulating our research from similar work being done elsewhere, by creating such a seemingly specialised forum:

If transnational film studies can indeed be imagined as an academic field, now with its own dedicated journal to boot, it is, within the reality of institutional and disciplinary practices, at best a sub-field with an expanding geography and population, and, at worst, a ghetto whose particular interests would continue to struggle to be perceived - and accepted - as bearing a more general or even universal application and relevance. (Higbee and Lim 2010, 17)

Indeed, it seemed clear to us that studies of the instability of national identities and their cinematic manifestations could not be framed as linear rejections of nationally constituted disciplines, since many 'area studies' fields were embracing almost identical issues, retaining a focus on the 'local' while situating such concerns ever more within the 'global'. Were imaginary disciplinary boundaries being erected and policed by such enterprises as this journal and our SIG? If so, how best could our network strive to traverse these barriers?

By bringing together leading scholars from across these disciplines - with 'position pieces' from Tim Bergfelder, Deborah Shaw, Lúcia Nagib and Flavia Laviosa, followed by open discussion between approximately seventy participants - the workshop encompassed discussions around notions of a shared cinematic imaginary, cinematic tropes that recur across historical and geographical contexts, and the fluctuations of specific 'transnationalisms' within particular territories and cultural moments. We thereby considered how future routes of collaboration might bridge the tension between deep understanding of cultural specificity, specialised contextual knowledge or linguistic ability on the one hand, and a recognition of the movable, unstable nature of national identities and outlooks on the other.

The fact that this lively workshop - despite being scheduled first thing in the morning on the usually quiet opening day of the conference - turned out to be 'standing room only' alerted us to the rich diversity of interests we needed to consider. By this point in the SIG's development, it had, therefore, become abundantly clear to us that, very far from catering to an overlooked niche, we were acting as a forum for an expansive area of study, traversing numerous specialisms. Certainly, Shaw's 2017 reflection on the field (cited at the start of this article) suggests that the issue raised by Higbee and Lim about the potential ghettoisation of 'transnational cinemas' has now at least partially been addressed, as it has opened up to area studies and other branches of film and cinema analysis (including, as previously mentioned, our own areas of study in genre and popular cinemas). This, however, raises another issue: if 'transnational 
cinema studies' indeed encompasses almost every area of film studies, is it a tautological field? If cinema is and has always been 'transnational' by definition, what are we studying, and what fresh insights are we offering?

It seemed apparent to us that, if we were to offer meaningful answers to these questions, we would have to move on from abstract discussions of definition, and introduce workshops that were practically oriented around pedagogical and research methodologies.

\section{'Teaching transnational cinemas' workshop (SCMS 2015 - Montreal)}

While there had been a significant number of publications and conferences devoted to theoretical and historical research on transnational cinemas by this stage, there had been relatively few forums where scholars had systematically interrogated the pedagogical implications of this research. ${ }^{3}$ We were aware that many scholars were grappling with how exactly to put the theoretical insights of this burgeoning field into practice in designing their syllabi and preparing their classes. Therefore, we set up a workshop at the Montreal conference for scholars to come together and reflect upon the implications that a transnational approach has for our teaching. What alternatives can we devise to a curriculum structured around discrete national cinemas? How might we best introduce students to the challenging questions raised by transnational approaches related to the politics of cross-cultural exchange, the interface of the global and the local, and the limitations of national cinematic frameworks? To what extent can we draw together insights from across the discipline in order to overcome some of the challenges we ourselves have faced in teaching transnational cinemas?

While there has been a long-established tradition of teaching modules on 'world cinema', with each session generally focused on individual discrete national traditions, the shift towards considerations of the transnational has meant that scholars are often faced with the challenge of adequately addressing this global polycentrism in a way that still retains a grounding in cultural specificity - not to mention the many practical issues involved in teaching classes that move beyond a single national context. The four panellists - Iain Robert Smith, Mark Gallagher, Chelsea Wessels and Matthew Holtmeier ${ }^{4}$ were each given time to discuss and reflect upon their own experiences teaching modules on transnational cinemas, and this contained numerous insights into the challenges resulting from students being asked to negotiate with at least two different national cultures in each session. It was clear that, without the concept of the 'national' to help structure and focus our teaching, we were all grappling with alternative frameworks that could help ground a potentially vague 'transnational' perspective. Indeed, it soon became evident that the most valuable purpose of the workshop was in debating and reflecting upon the various strategies we each use to integrate the more abstract insights from transnational film studies scholarship into our pedagogical practice. One of the most promising threads of the discussion centred upon the potential of using a comparative approach to discuss particular themes and genres across a range of national contexts. With a number of speakers citing Dudley Andrew's proposed 'Atlas of World Cinema' as a possible model for a transnational perspective that would trace cross-cultural influences across various national industries in order to 'track a process of cross-pollination that bypasses national directives' (Andrew 2006, 19), the workshop's attendees debated the relative strengths and 
weaknesses of replacing a national framework with a thematic or generic focus. While various objections were raised to the idea that a module on transnational cinemas necessarily required a comparative topic-based structure, it was nevertheless clear that one advantage to this approach was that it would help students to make links between otherwise seemingly isolated national cases. By opening up this much-needed debate, the workshop offered scholars from a range of different sub-disciplines an opportunity to grapple with the relative efficacy of the pedagogical techniques that they are each using to teach transnational cinemas, and to share successful strategies that help retain some level of cultural specificity while still addressing the politics of the transnational.

\section{'Video essays in transnational cinema studies' workshop (SCMS 2016 - Atlanta)}

As our tenure as co-chairs of the SIG neared its end-point, it was increasingly clear to us that, though analysis of the movable and unstable nature of national or cultural identities was increasingly de rigueur in film studies, certain practical barriers remained. In particular, the desire to understand the nuances of cultural transfer still existed in tension with the necessity for specialised contextual or linguistic knowledge, and this was still being seen as a barrier to research and teaching in the field. As scholarly methodologies continue to evolve, we asked ourselves, how might new opportunities to overcome such hurdles present themselves? The notable success of the videographic journal [in] Transition seemed to offer a pertinent avenue of investigation in this regard. This collaboration between MediaCommons and SCMS's official publication Cinema Journal (since renamed Journal of Cinema and Media Studies) was the first peer-reviewed academic journal of videographic film and moving image studies, and had recently won the 2015 Anne Friedberg Innovative Scholarship Award of Distinction. As its star was so visibly rising, the time seemed ripe to consider pressing questions around the video essay's relationship to written forms of scholarship, and the implications of that relationship for the field of transnational cinema studies.

This workshop, therefore, brought together video essay practitioners who sought to address the above issues through their work, to explore the extent to which audiovisual scholarship can help us to examine cultural and stylistic dialogues within and between national cinemas. Might a medium that does not rely on written language to the same extent as traditional academic articles or books facilitate fresh insights into the cultural relationships between films, through audiovisual, poetic or rhythmic manipulation? The workshop was practical in focus, with an emphasis on the development and sharing of resources for teaching and research in the field of transnational cinema.

Chaired by Tracy Cox-Stanton, the workshop consisted of videographic work by Nicolas Poppe, Michael Talbott, Austin Fisher and Jeffrey Middents (and a further piece composed in absentia by Catherine Grant $)^{5}$ being presented to the participants, many of whom were themselves established video essay practitioners (including Jason Mittell, ${ }^{6}$ Corey Creekmur and William Brown). Discussions revolved variously around the extent to which such resources can be incorporated into professional practice, as well as methodological considerations around translation, adaptation and remediation in video essay production, such as editing techniques and split-screen composition. One repeated reference point was Eric Faden's 'Manifesto for Critical Media', which argues for the value to film scholarship of dealing 'with the very same problems [of image, voice, pacing, text, sound, music, montage and rhythm] that our subjects deal with' (Faden 2008). From the 
perspective of transnational cinema studies, the workshop discussions suggested, such formal manipulation can reveal ways in which stylistic elements are shared or juxtaposed between films and across linguistic and cultural barriers. Simultaneously, however, the extent to which a purely rhythmic (that is, voiceover free) videographic format can ever do justice to the nuances of cultural identities was brought into doubt. The workshop concluded with the suggestion that such work is of necessity an experimental format, whose innate challenges and imperfections reveal much about the difficulties of transnational dialogue and should, therefore, themselves be the object of study.

\section{The critical roundtable}

Given the necessarily fleeting and ephemeral nature of conference panels and workshops, we decided to mark the end of our tenure as SIG co-chairs in 2016 by inviting some of our panellists and discussants to participate in a published critical roundtable where they would each answer some of the questions that were most often being raised in our sessions (Fisher and Smith 2016). While our SIG was partly designed to move beyond questions of definition, we felt that it was necessary to start by asking each scholar to provide their own definition of transnational cinema. What was particularly interesting about this exercise was that while the term can sometimes seem to mean 'anything and everything that the occasion would appear to demand' (Hjort 2009, 12), our respondents were actually remarkably consistent in how they each conceptualise the transnational. Rather than the term being used to refer to a specific form of cinema such as international co-productions or diasporic filmmaking, the responses instead highlighted transnational cinema as primarily a scholarly approach or perspective. Will Higbee, for example, views 'transnational cinema as an approach to studying the global circulation of film as a cultural and industrial art form in terms of production, distribution and exhibition/reception' while Lucy Mazdon argues that the most productive definition 'is an understanding of transnational cinema as an approach, a methodology, a way of thinking about cinema rather than simply an object of study'. Moreover, our respondents tended to position this transnational approach as having the potential to challenge existing national biases, with Tim Bergfelder arguing that it is at its most interesting where it is used to question and if necessary debunk some of the exclusionary narratives and historical practices that underscore the majority of national film histories', and Andrew Higson proposing that to 'focus on the transnational is [...] a way of challenging the national bias in much film scholarship, which often assumes that the national is a self-contained entity when the evidence is often to the contrary'.

Nevertheless, there was some debate amongst our respondents about whether the transnational turn within film scholarship had displaced other (arguably more political) approaches such as postcolonialism. Rosalind Galt suggested that this was 'a valid criticism insofar as there certainly are some strands in transnational film scholarship that are precisely not engaged in thinking the postcolonial, the political, or the work of structural critique' but that for her, 'the transnational is always political because it demands that we think about the relationships of cinema and geopolitics through, between, and beyond the state'. Similarly, Higbee argued that the 'transnational only eschews or elides questions of politics and (imbalances of) power if we let it' while Bergfelder proposed that the transnational 'can and indeed should be used to interrogate and challenge myths of national 
exceptionalism, "purity" and "containment", and that seems to me to be an important political task today more than ever'. Andrew Higson, on the other hand, expressed some scepticism about whether there is a necessary politics underpinning an engagement with the transnational' although he nevertheless proposed that recognising the wealth of evidence of transnational dynamics throughout cinematic history inevitably 'challenges those who define the national in terms of purity, exclusivity and self-containedness'.

Significantly, when we curated our critical roundtable in early 2016, this was a period leading up to the Brexit vote and the election of Donald Trump later that year. The response that most clearly resonated with that political context came from Lucy Mazdon who noted that,

Rather than sharing anxieties about the transnational turn's displacement of other approaches, I would argue for the vital necessity of an approach to cinema and other cultural forms which questions and problematises nations and nationalism. As we approach the EU referendum in the UK and Donald Trump with his calls for a wall between the US and Mexico makes significant headway in his bid to be the Republican candidate for the US presidency, so an engagement with the transnational, underpinned by an interrogation of the discourse and ideologies of nationalism, seems ever more imperative.

Looking back at the responses from our respondents, it is clear that the question of a political underpinning to transnational scholarship is tied up with a broader concern about our role as film scholars within the context of resurgent nationalisms. In the words of Kathleen Newman, a transnational approach asks us to consider 'what can the study of cinema tell us about how to make the world a better place?'. While this was a question that was rarely expressed so explicitly in our sessions, we nevertheless believe that this issue underpinned much of the scholarly debate throughout our tenure as SIG co-chairs.

\section{Conclusion}

It seems somehow inappropriate to write a 'conclusion' for a piece, such as this one, that is taking stock of an ongoing process of development. Our reflections here merely record a snapshot of this process. This, of course, is as it should be in such an organic and vibrant field of study as the one for which this journal caters. To close, we would, therefore, like to turn our attention to the fact that the SIG has continued to develop and grow since we handed it over to the new co-chairs Elena Caoduro and Raphael Raphael in 2017.

If, as our findings above have indicated, our tenure at the helm of this group led in some cases to our own areas of specialism being unconsciously privileged, the current co-chairs are making tangible efforts to widen the field of study. In line with Cinema Journal's 2018 name change to Journal of Cinema and Media Studies, members of the SIG were balloted over whether the group's name should be altered to encompass broader fields of media studies beyond cinema (this also, of course, comes at a time when this very journal is changing its name along similar lines: from Transnational Cinemas to Transnational Screens). Though the SIG's name change was ultimately not voted through, Caoduro and Raphael have indicated that their panel sponsorship policies will be more inclusive, to take account of a broader sweep of transnational media. This suggests that the field's definitional issues are themselves evolving, from the earlier focus on the word 'national' to an examination of the word 'cinema' in an era when streaming technologies are increasingly challenging 
received boundaries between screen-based media. This is yet another sign that our field is organic and ever-changing. If such a field is to survive, it must of course also nurture the next generation of scholars, and it is therefore pleasing to see the new SIG regime continuing the excellent work of our Graduate Student Representative, Tim Jones, with the new occupant of the role Anirban Baishya organising the SIG's inaugural student writing award in 2019.

Looking back over our period of leading the 'Transnational Cinemas' scholarly interest group has therefore revealed that a shift towards thinking about the field's practical applications for both research and teaching has taken place, and that our various workshops, panels and outputs played a part (whether as symptom or cause we are as yet unsure) in this broader process. While definitional debates will perhaps never truly subside, it is nevertheless a sign of a healthy and vigorous field of enquiry that this 'second phase' is tangibly under way.

\section{Notes}

1. Deborah Shaw has since made a similar case, in the process providing a more rigorous evidence base to corroborate our somewhat subjective observation: 'In addition to migration and its influence on European cinemas, many scholars since the mid-2000s have applied a transnational framework to their research on regional or national cinemas throughout the world. This includes studies of East Asian cinemas (Hunt and Leung 2008; Morris et al. 2006; Berry 2010), Bollywood (Kaur and Sinha 2005; Dudrah 2012), Irish film (McIlroy 2007), Nordic Cinema (Nestingen and Elkington 2005), African cinemas (Krings and Okome 2013), Polish cinema (Mazierska and Goddard 2014), Hispanic Cinema (Dennison 2013) and Asian and Australian cinema (Khoo et al. 2013)' (Shaw 2017, 292).

2. It is, therefore, to be regretted that an unintended consequence of SCMS's (in many other ways entirely justified) decision to allow each member to participate in only one panel or workshop at the conference has seen the decline of the valuable workshop format. The 2019 programme includes only seven such sessions out of several hundred. The recent introduction of 'seminars' on the Sunday morning has perhaps mitigated this, however.

3. Katarzyna Marciniak and Bruce Bennett's collection Teaching Transnational Cinema would not be published until 2016. This volume affirms the value of this workshop by mentioning our SIG as evidence for the increasing willingness of film scholars to engage with 'philosophical debates about the strategies, methodologies, politics, and conceptual underpinnings of using transnational cinema in the classroom' (Marciniak and Bennett 2016, 13).

4. We selected the four panellists to capture a range of experiences in teaching modules on cinematic transnationalism - from early career researchers such as Chelsea Wessels (Cornell University) and Mathew Holtmeier (Ithaca College) who were attempting to introduce transnational cinema topics into established world cinema curricula, through to more established scholars such as Mark Gallagher (University of Nottingham) who has extensive experience teaching a module on 'Transnational Media' that explores transnationalism across a range of screen-media.

5. These panellists were chosen for the fact that each had recently used video essay work to explore the relationships between films from diverse cultural backgrounds, and the extent to which audiovisual scholarship might be able to traverse the linguistic barriers between them.

6. Mittell would subsequently be instrumental to the founding of SCMS's 'Digital Humanities and Videographic Criticism' SIG: an undertaking that again affirms the timeliness of this workshop. 


\section{Disclosure statement}

No potential conflict of interest was reported by the authors.

\section{Notes on contributors}

Austin Fisher is Principal Academic in Media Production at Bournemouth University. He is author of Blood in the Streets: Histories of Violence in Italian Crime Cinema (EUP, 2019) and Radical Frontiers in the Spaghetti Western (I.B. Tauris, 2011), and editor of Spaghetti Westerns at the Crossroads (EUP, 2016). He is also co-editor (with Johnny Walker) of both Grindhouse: Cultural Exchange on 42nd Street, and Beyond (Bloomsbury, 2016) and Bloomsbury's 'Global Exploitation Cinemas' book series.

Iain Robert Smith is Lecturer in Film Studies at King's College London. He is author of The Hollywood Meme: Transnational Adaptations in World Cinema (EUP, 2016) and co-editor of the collections Transnational Film Remakes (with Constantine Verevis, EUP, 2017) and Media Across Borders (with Andrea Esser and Miguel Bernal-Merino, Routledge, 2016). In 2018, he was selected as an AHRC/BBC New Generation Thinker.

\section{References}

Andrew, D. 2006. "An Atlas of World Cinema." In Remapping World Cinema: Identity, Culture and Politics in Film, edited by S. Dennison and S. H. Lim, 19-29. New York and London: Wallflower Press.

Berry, C. 2010. "What Is Transnational Cinema? Thinking from the Chinese Situation." Transnational Cinemas 1 (2): 111-127. doi:10.1386/trac.1.2.111_1.

Decker, L. 2017. "Review of the Transnational Cinemas Special Interest Group Panels at the Society for Cinema and Media Studies Conference Atlanta, Georgia, USA, 30 March3 April 2016." Transnational Cinemas 8 (2): 164-170. doi:10.1080/20403526.2016.1232974.

Dennison, S., ed. 2013. Contemporary Hispanic Cinema: Interrogating Transnationalism in Spanish and Latin American Film. Woodbridge: Tamesis.

Dudrah, R. 2012. Bollywood Travels: Culture, Diaspora and Border Crossings in Popular Hindi Cinema. London: Routledge.

Faden, E. 2008. “A Manifesto for Critical Media.” Mediascape, Spring 2008. www.tft.ucla.edu/ mediascape/Spring08_ManifestoForCriticalMedia.html.

Fisher, A., and I. R. Smith. 2016. "Transnational Cinemas: A Critical Roundtable." Frames Cinema Journal, 9. http://framescinemajournal.com/article/transnational-cinemas-a-criticalroundtable/.

Higbee, W., and S. H. Lim. 2010. "Concepts of Transnational Cinema: Towards a Critical Transnationalism in Film Studies.” Transnational Cinemas 1 (1): 7-21. doi:10.1386/ trac.1.1.7/1.

Hjort, M. 2009. "On the Plurality of Cinematic Transnationalism." In World Cinemas, Transnational Perspectives, edited by K. Newman and N. Durovicová, 12-33. New York and London: Routledge.

Hunt, L., and W. Leung, eds. 2008. East Asian Cinemas: Exploring Transnational Connections on Film. London: I. B. Tauris

Kaur, R., and A. J. Sinha, eds. 2005. Bollyworld: Popular Indian Cinema Through a Transnational Lens. New Delhi: Sage

Khoo, O., B. Smaill, and A. Yue. 2013. Transnational Australian Cinema: Ethics in the Asian Diasporas. Lanham, MD: Lexington Books.

Krings, M., and O. Okome, eds. 2013. Global Nollywood: The Transnational Dimensions of an African Video Film Industry. Bloomington, IN: Indiana University Press. 
Marciniak, K., and B. Bennett. 2016. "Introduction: Teaching Transnational Cinema Politics and Pedagogy." In Teaching Transnational Cinema, edited by K. Marciniak and B. Bennett, 1-35. New York: Routledge.

Mazierska, E., and M. Goddard, eds. 2014. Beyond the Border: Polish Cinema in a Transnational Context. New York: Rochester University Press.

McIlroy, B., ed. 2007. Genre and Cinema: Ireland and Transnationalism. London: Routledge.

Morris, M., S. Leung Li, and S. Chan Ching-Kiu. 2006. Hong Kong Connections: Transnational Imagination in Action Cinema. Durham, NC: Duke University Press.

Nagib, L. 2006. "Towards a Positive Definition of World Cinema." In Remapping World Cinema: Identity, Culture and Politics in Film, edited by S. Dennison and S. H. Lim, 30-37. New York and London: Wallflower Press.

Shaw, D. 2013. "Deconstructing and Reconstructing 'Transnational Cinema'." In Contemporary Hispanic Cinema: Interrogating the Transnational in Spanish and Latin American Film, edited by S. Dennison, 47-65. Woodbridge: Tamesis Books.

Shaw, D. 2017. "Transnational Cinema: Mapping a Field of Study." In The Routledge Companion to World Cinema, edited by R. Stone, P. Cooke, S. Dennison, and A. Marlow-Mann, 290-298. New York and London: Routledge. 